\title{
ChemComm
}

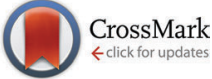

Cite this: Chem. Commun., 2015, 51,10494

Received 20th April 2015

Accepted 11th May 2015

DOI: $10.1039 / c 5 c c 03220 b$

www.rsc.org/chemcomm

\section{Ternary chalcogenide micro-pseudocapacitors for on-chip energy storage $\uparrow$}

\author{
Narendra Kurra, $\ddagger$ Chuan Xia $\$$ M. N. Hedhili and H. N. Alshareef*
}

\begin{abstract}
We report the successful fabrication of a micro-pseudocapacitor based on ternary nickel cobalt sulfide for the first time, with performance substantially exceeding that of previously reported micro-pseudocapacitors based on binary sulfides. The CoNi $\mathrm{S}_{4}$ micro-pseudocapacitor exhibits a maximum energy density of $18.7 \mathrm{~mW} \mathrm{~h} \mathrm{~cm}^{-3}$ at a power density of $1163 \mathrm{~mW} \mathrm{~cm}^{-3}$, and opens up an avenue for exploring a new family of ternary oxide/sulfide based micro-pseudocapacitors.
\end{abstract}

Microsupercapacitors (MSCs) are promising devices for next generation on-chip energy storage due to their high power density, which can complement high energy density batteries. ${ }^{1-3}$ Additional attributes of MSCs include excellent rate capability, a long cycling lifetime, and superior volumetric capacity to their conventional sandwich counterparts. ${ }^{3,4}$ The planar configuration of MSCs can allow robust integration with functional electronic devices such as microsensors and biomedical implants as micro-power units. ${ }^{5-7}$ Hence, a great deal of research has been focused on a variety of nanostructured electroactive materials that are amenable to fabricate in-plane MSCs. ${ }^{3,4}$

Various MSCs based on conducting porous carbon were fabricated employing conventional photolithography and deposition or etching schemes. For example, high surface area carbon forms such as activated, ${ }^{8}$ carbide derived, ${ }^{2}$ onion like ${ }^{9}$ and carbon nanotubes $^{10}$ have been patterned employing photolithography followed by deposition methods such as ink-jet printing, electrophoretic and spray deposition. Further, high temperature chemical vapor deposition (CVD) was also employed in growing carbon nanotubes (CNTs) and graphene or both, selectively over the patterned current collectors. ${ }^{11,12}$ of late, due to compatible solution processability, graphene oxide (GO) has become attractive candidate material for making MSCs employing an etching scheme in a photolithography technique ${ }^{13}$ or innovative direct

Materials Science and Engineering, King Abdullah University of Science and Technology (KAUST), Thuwal 23955-6900, Saudi Arabia.

E-mail: husam.alshareef@kaust.edu.sa

$\dagger$ Electronic supplementary information (ESI) available. See DOI: $10.1039 / \mathrm{c5cc03220 \textrm {b }}$ \$ Contributed equally to the work. laser scribing methods. ${ }^{14,15}$ Further, in order to improve the limited capacitance of carbon based MSCs, several pseudocapacitive materials including metal oxides/hydroxides $\left(\mathrm{RuO}_{2}, \mathrm{MnO}_{2} \text { and } \mathrm{Ni}(\mathrm{OH})_{2}\right)^{16-18}$ and even conducting polymers (PPY, PANI, PEDOT) ${ }^{19-22}$ were employed to fabricate high capacity micro-pseudocapacitors. These pseudocapacitive materials can undergo fast redox reactions at their nanostructured surfaces, contributing to the higher values of capacity and hence energy density. ${ }^{16-22}$

Recently, new electrode materials in the form of binary and ternary sulfides have been explored as potential candidates for pseudocapacitors. ${ }^{23-25}$ However, most of the studies have been focused on their synthesis and investigation of their electrochemical performance in 3-electrode configuration. To exploit the practical usage of these new materials, it is highly desirable to build energy storage devices in a 2-electrode configuration. ${ }^{25,26}$ In-plane MSCs based on binary metal sulfides such as $\mathrm{MoS}_{2}$ and $\mathrm{VS}_{2}$ have been fabricated, which showed an areal cell capacitance of 5-8 $\mathrm{mF} \mathrm{cm}^{-2} \cdot{ }^{27,28}$ Moreover, nanostructured sulfides, in particular, ternary nickel cobalt sulfides, have become outstanding electrode materials due to their higher conductivity and richer redox reactions than the single component sulfides due to contributions from nickel and cobalt ions. ${ }^{23-25}$ In addition, it was demonstrated that these ternary cobalt nickel sulfides exhibit higher electronic conductivity and richer redox reactions than their ternary oxide counter-parts, resulting in higher capacity values. ${ }^{29}$ Here, we demonstrate the fabrication of ternary sulfide micro-pseudocapacitors with excellent volumetric capacitance and energy density.

We report the fabrication of a nanostructured ternary cobalt nickel sulfide micro-pseudocapacitor employing electrochemical co-deposition over the $\mathrm{rGO} / \mathrm{Au} /$ patterned photoresist. The rGO free-standing films are prepared through vacuum filtration from its dispersion. Before doing lift-off, ternary cobalt nickel sulfide was electrodeposited to ensure uniform deposition over the entire area. The resulting $\mathrm{CoNi}_{2} \mathrm{~S}_{4}$ MSC exhibits a volumetric capacitance of $211 \mathrm{~F} \mathrm{~cm}^{-3}$ (an areal capacitance of $11.6 \mathrm{mF} \mathrm{cm}^{-2}$ ), corresponding to an energy density of $18.7 \mathrm{~mW} \mathrm{~h} \mathrm{~cm}^{-3}$ at a power density of $1163 \mathrm{~mW} \mathrm{~cm}^{-3}$. This is the best reported performance of any sulfide based micro-pseudocapacitor. 


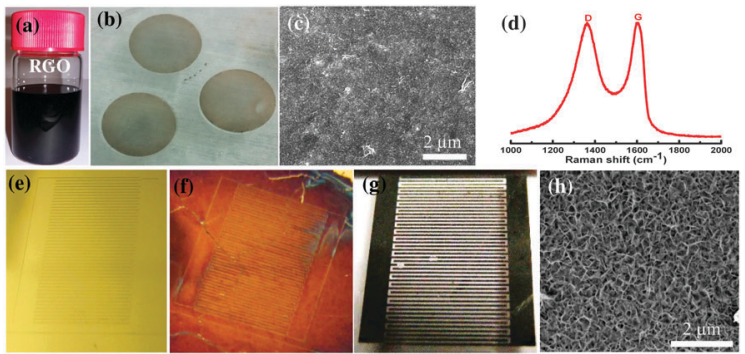

Fig. 1 Digital photographs showing (a) rGO dispersion, (b) freely floating rGO thin films obtained through vacuum filtration, (c) SEM micrograph showing the morphology of rGO film, (d) Raman spectrum of rGO. Photographs showing (e) Au coated patterned photoresist, (f) transferring of $r G O$ onto Au/patterned photoresist, (g) electrochemical co-deposition of $\mathrm{CoNi}_{2} \mathrm{~S}_{4}$ followed by liftoff in resulting $\mathrm{CoNi}_{2} \mathrm{~S}_{4}$ interdigitated electrodes, (h) nanostructured morphology of $\mathrm{CoNi}_{2} \mathrm{~S}_{4}$.

Fig. 1a shows the rGO dispersion (described in the ESI $\dagger$ ) that was used to obtain rGO thin films by vacuum filtration over the anodic alumina membrane. ${ }^{30-32}$ The alumina membrane was subsequently dissolved in $3 \mathrm{M} \mathrm{NaOH}$ to result in the freely floating film of rGO over the water bath as shown in Fig. 1b. This rGO film is comprised of tightly packed small flakes (lateral dimensions, $200 \mathrm{~nm}$ ) giving rise to innumerable edges, domain boundaries, and interfaces. Raman spectrum of rGO film shows broad D and G bands centered at 1367 (FWHM, $206 \mathrm{~cm}^{-1}$ ) and $1598 \mathrm{~cm}^{-1}$ (FWHM, $91 \mathrm{~cm}^{-1}$ ), respectively. The D band originates from the presence of defects and functional groups while the $\mathrm{G}$ band corresponds to symmetric stretching of the $\mathrm{sp}^{2}$ carbon lattice with $E_{2 \mathrm{~g}}$ symmetry. ${ }^{33}$ The $I_{\mathrm{D}} / I_{\mathrm{G}}$ ratio of rGO films was found to be in the range of $0.8-0.9$ and the $\mathrm{sp}^{2}$ crystallite size was estimated using the below formula, ${ }^{34}$ and was found to be $10-15 \mathrm{~nm}$. $E_{\text {laser }}$ is the laser excitation energy $(\mathrm{eV})$ in the following equation:

$$
L_{\mathrm{a}}(\mathrm{nm})=560 / E_{\text {laser }}^{4}\left(I_{\mathrm{D}} / I_{\mathrm{G}}\right)^{-1}
$$

We have followed the conventional photolithography liftoff protocol to fabricate ternary nickel cobalt sulfide micropseudocapacitors (the detailed fabrication process is illustrated in the ESI, $\dagger$ Fig. S1). Initially, a metal coated patterned photoresist chip was employed as a platform to transfer the free-standing rGO film as shown in Fig. 1e and f. Reduced graphene oxide (rGO) provides a functional conducting graphitic platform which, when used as current collector, improves the nucleation and growth of pseudocapacitive materials compared to metal current collectors. ${ }^{35}$ Recently, Du et al. have demonstrated a physical approach for synthesizing a nanocomposite of $\mathrm{CoNi}_{2} \mathrm{~S}_{4}$-graphene with excellent electrochemical performance. ${ }^{36}$ We have found that compared to metal surfaces such as $\mathrm{Au}$ or $\mathrm{Ni}$, the functional rGO surface helps in the uniform growth of ternary sulfides (Fig. S2, ESI $\dagger$ ). It was observed that the growth of $\mathrm{CoNi}_{2} \mathrm{~S}_{4}$ was non-uniform over the $\mathrm{Au}$ current collectors as is evident from the SEM micrographs shown in Fig. S2 (ESI $\dagger$ ). However, Au acts as a conductive support/ current collector while the rGO layer helps in the homogenous and uniform nucleation and growth of $\mathrm{CoNi}_{2} \mathrm{~S}_{4}$ during the electrochemical co-deposition process. Electrochemical co-deposition was carried out before photoresist lift-off to ensure uniform electric field and uniform growth of $\mathrm{CoNi}_{2} \mathrm{~S}_{4}$ over the entire chip. Doing the photoresist lift-off before electrodeposition would have created irregular electric fields and non-uniform growth of the $\mathrm{CoNi}_{2} \mathrm{~S}_{4}$. The strong adherence of nickel cobalt sulfide onto the rGO film is evident since the final step of liftoff involved rigorous ultrasonication to make the $\mathrm{CoNi}_{2} \mathrm{~S}_{4} / \mathrm{rGO}$ finger electrodes. It is obvious from the SEM micrograph shown in Fig. $1 \mathrm{~h}$ that the electrodeposited $\mathrm{CoNi}_{2} \mathrm{~S}_{4}$ layer has a uniform monolithic morphology. We have considered rGO thin film as a platform for growing $\mathrm{CoNi}_{2} \mathrm{~S}_{4}$ heterostructures with interdigitated electrode patterns in evaluating its electrochemical performance in a 2-electrode configuration.

XPS analysis was carried out in order to determine the chemical composition of the sample and the oxidation state of detected elements. High resolution XPS spectra of Co 2p, Ni 2p, and S 2p core levels have been recorded and are shown in Fig. 2. The high resolution XPS spectra match well with those obtained for ternary nickel cobalt sulfides $\mathrm{CoNi}_{2} \mathrm{~S}_{4}{ }^{37}$ and $\mathrm{NiCo}_{2} \mathrm{~S}_{4} \cdot{ }^{38,39}$ Precise distinction between the two sulfides is difficult due to the similarities of the shape and binding energies of the Co 2p, Ni 2p and S 2p core levels. The elemental composition was obtained using XPS by applying the appropriate relative sensitivity factors (RSFs) to the integrated peak areas of specific core levels for the different elements. The atomic ratio $\mathrm{S} / \mathrm{Ni} / \mathrm{Co}$ was estimated to be $4: 2: 1$, which can be assigned to $\mathrm{CoNi}_{2} \mathrm{~S}_{4}$. The Ni $2 \mathrm{p}_{3 / 2}$ portion of the Ni $2 \mathrm{p}$ spectrum was fitted using three components.

The Ni $2 \mathrm{p}_{3 / 2}$ components observed at 852.9 and $855.7 \mathrm{eV}$ correspond to $\mathrm{Ni}^{2+}$ and $\mathrm{Ni}^{3+}$ species, respectively. ${ }^{37,40}$ The third $\mathrm{Ni} 2 \mathrm{p}_{3 / 2}$ component located at $861.3 \mathrm{eV}$ is related to a shake-up satellite of $\mathrm{Ni}^{3+}$ species. ${ }^{37,40}$ The Co $2 \mathrm{p}_{3 / 2}$ part of the Co $2 \mathrm{p}$ spectrum was fitted using three components as well. The Co $2 \mathrm{p}_{3 / 2}$ component observed at 778.2 is attributed to $\mathrm{Co}^{3+}$ species, while the components located at 781.0, and 786. $3 \mathrm{eV}$ correspond to the $\mathrm{Co}^{2+}$ main peak accompanied with its shake-up satellite, respectively. ${ }^{37,40}$ For the $S$ 2p high resolution XPS spectrum, the peak observed at $161.3 \mathrm{eV}$ corresponds to the $S 2 p_{3 / 2}$ core level, which is typical of metal sulfur bounds in the ternary metal sulfides ${ }^{41}$ and consistent with nickel and
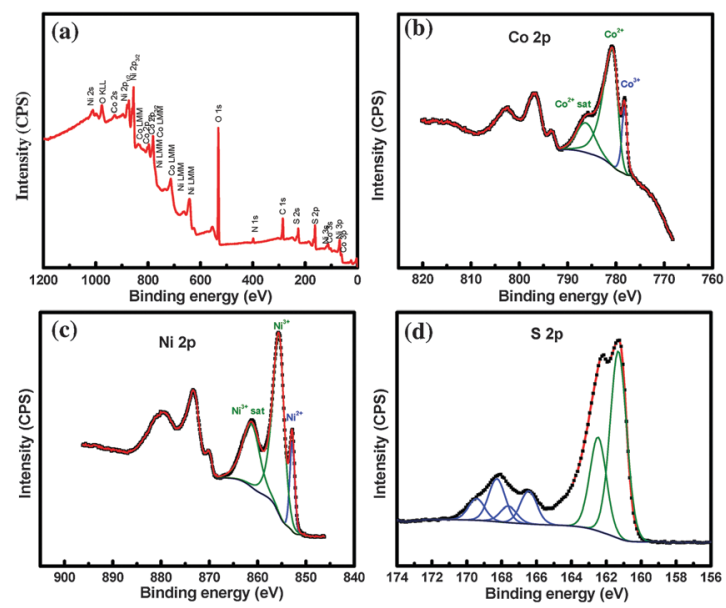

Fig. 2 X-ray photoelectron spectroscopy (XPS) of $\mathrm{CoNi}_{2} \mathrm{~S}_{4}$ (a) survey scan and core-level spectra of (b) Co $2 p$, (c) Ni $2 p$ and (d) $S 2 p$. 

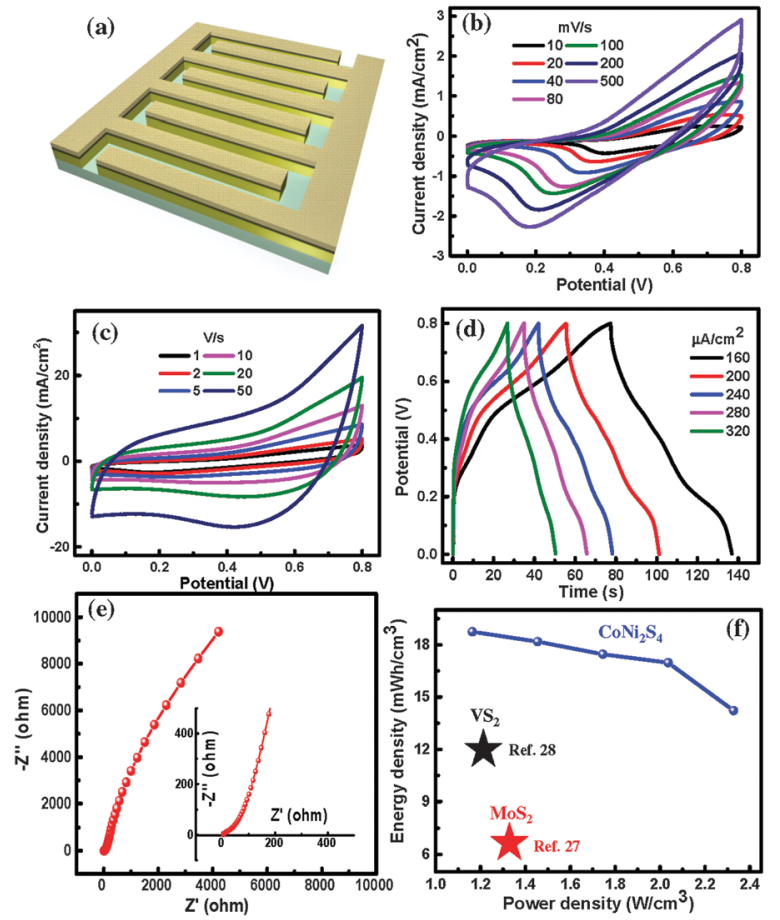

Fig. 3 (a) Schematic showing the interdigitated electrodes of $\mathrm{CoNi}_{2} \mathrm{~S}_{4}$ (b) and (c) $\mathrm{CVs}_{\text {s }} \mathrm{CoNi}_{2} \mathrm{~S}_{4} \mathrm{MSC}$ in $1 \mathrm{M} \mathrm{KOH}$ in a 2-electrode configuration. (d) Charge-discharge curves at different current densities. (e) Impedance spectra of the device, the inset shows the high frequency region of the spectrum. (f) Ragone plot comparing the energy and power densities of the $\mathrm{CoNi}_{2} \mathrm{~S}_{4}$ micro-pseudocapacitor with respect to $\mathrm{MoS}_{2}$ and $\mathrm{VS}_{2}$ micropseudocapacitors reported in the literature.

cobalt sulfides. ${ }^{41}$ The $\mathrm{S} 2 \mathrm{p}_{3 / 2}$ peaks observed at $166.5 \mathrm{eV}$ and $168.3 \mathrm{eV}$ are attributed to surface sulfur with high oxide states, to sulfites and sulfates, respectively.

The electrochemical performance of the $\mathrm{CoNi}_{2} \mathrm{~S}_{4}$ micropseudocapacitor was tested in a 2-electrode configuration in $1 \mathrm{M} \mathrm{KOH}$ electrolyte. Unlike the EDLC behavior of an rGO MSC where the charge is stored through the electrostatic accumulation of electrolytic ions, redox behavior is observed from the $\mathrm{CoNi}_{2} \mathrm{~S}_{4}$ MSC (see Fig. S3, ESI $\dagger$ ). As shown in Fig. 3a, the redox peaks appear at different scan rates due to the redox behavior of $\mathrm{Co}^{+4} / \mathrm{Co}^{+3} / \mathrm{Co}^{+2}$ and $\mathrm{Ni}^{+3} / \mathrm{Ni}^{+2}$ couples, mediated by the hydroxyl ions $\left(\mathrm{OH}^{-}\right)$in the electrolyte. Since sulfur belongs to the same group of oxygen, $\mathrm{OH}^{-}$ions can induce electrochemical oxidation and reduction of $\mathrm{CoNi}_{2} \mathrm{~S}_{4}$ in alkaline medium similar to that of metal oxides/hydroxides. However, it is difficult to deconvolute the contributions of $\mathrm{Ni}$ and $\mathrm{Co}$ due to the broad nature of redox peaks, most probably due to reversible formation of redox couples such as $\mathrm{NiS} / \mathrm{NiS}(\mathrm{OH})$ and $\mathrm{CoS} / \mathrm{CoS}(\mathrm{OH}) / \mathrm{CoSO}$. At a scan rate of $10 \mathrm{mV} \mathrm{s}^{-1}, \mathrm{CoNi}_{2} \mathrm{~S}_{4}$ shows an areal cell capacitance of $11.6 \mathrm{mF} \mathrm{cm}{ }^{-2}$, which is superior to binary metal oxide (areal cell capacitance of 1-5 $\left.\mathrm{mF} \mathrm{cm} \mathrm{cm}^{-2}\right)$ and sulfide $\left(\mathrm{VS}_{2}, \mathrm{MoS}_{2} ; C_{\mathrm{A}}=\right.$ 4-8 $\mathrm{mF} \mathrm{cm}^{-2}$ ) based micro-pseudocapacitors. It was found that the areal capacitance was gradually increasing from 1.7 to $11.6 \mathrm{mF} \mathrm{cm}{ }^{-2}$ (at a current density of $160 \mu \mathrm{A} \mathrm{cm}^{-2}$ ) due to more loading of $\mathrm{CoNi}_{2} \mathrm{~S}_{4}$ when the deposition cycles were increased from 1 to 6 (see Fig. S4, ESI $\dagger$ ). Due to the planar configuration of the $\mathrm{CoNi}_{2} \mathrm{~S}_{4}$ interdigitated electrodes, CVs were recorded even at higher scan rates of $1-50 \mathrm{~V} \mathrm{~s}^{-1}$ as shown in Fig. 3c. Similarly, charge-discharge curves of the $\mathrm{CoNi}_{2} \mathrm{~S}_{4}$ MSC at different current densities were recoded as shown in Fig. 3d. CD profiles are highly non-linear, clearly demonstrating the pseudocapacitive behavior of the $\mathrm{CoNi}_{2} \mathrm{~S}_{4}$ electrodes. We have found that this micro-pseudocapacitor exhibits an areal cell capacitance of $11.6 \mathrm{mF} \mathrm{cm}{ }^{-2}$ (thickness of $\mathrm{CoNi}_{2} \mathrm{~S}_{4} / \mathrm{rGO}$ is about $0.55 \mu \mathrm{m}$ ), which corresponds to a volumetric capacitance of $211 \mathrm{~F} \mathrm{~cm}^{-3}$, while the pristine rGO based MSC shows a much lower areal capacitance of $0.3 \mathrm{mF} \mathrm{cm} \mathrm{cm}^{-2}$ with a volumetric capacitance of $40 \mathrm{~F} \mathrm{~cm}^{-3}$. Cycling stability of the $\mathrm{CoNi}_{2} \mathrm{~S}_{4}$ MSC was tested by continuous charging-discharging at a current density of $320 \mu \mathrm{A} \mathrm{cm} \mathrm{cm}^{-2}$, which showed a capacitance retention of $80 \%$ after 5000 cycles with a coulombic efficiency of above $95 \%$ (see Fig. S5, ESI $\dagger$ ). Further, a solid state $\mathrm{CoNi}_{2} \mathrm{~S}_{4}$ MSC was fabricated by employing $\mathrm{PVA} / \mathrm{KOH}$ gel electrolyte, which exhibits an areal capacitance of $2.8 \mathrm{mF} \mathrm{cm}^{-2}$ (see Fig. S6, ESI $\dagger$ ). Thus, enhanced values of areal and volumetric capacitance of the $\mathrm{CoNi}_{2} \mathrm{~S}_{4}$ MSC are due to the pseudocapacitive nature unlike the EDLC behavior of carbon based MSCs. This volumetric capacitance is still higher than $\mathrm{MoS}_{2}$ MSC (178 $\mathrm{F} \mathrm{cm}^{-3}$ ). Thus, these ternary $\mathrm{CoNi}_{2} \mathrm{~S}_{4}$ with impressive redox contributions from the $\mathrm{Ni}$ and Co metals as well as facile ionic diffusion through the nanostructured electrodes give rise to higher volumetric capacitance. The impedance spectrum for the $\mathrm{CoNi}_{2} \mathrm{~S}_{4}$ micro-pseudocapacitor is shown in Fig. 3e. The presence of a semi-circle in the high frequency region is due to charge-transfer resistance across the electrode/electrolyte interface with an equivalent series resistance (ESR) of $5 \Omega$ (see the inset of Fig. 3e). An optimized $\mathrm{CoNi}_{2} \mathrm{~S}_{4}$ micro-pseudocapacitor exhibits a maximum energy density of $18.7 \mathrm{~mW} \mathrm{~h} \mathrm{~cm}^{-3}$ at a power density of $1163 \mathrm{~mW} \mathrm{~cm}^{-3}$. The energy density values are at least twice that of carbon ${ }^{8-15}$ and metal oxide based MSCs ${ }^{16,17}$ ( $E=1-10 \mathrm{~mW} \mathrm{~h} \mathrm{~cm}^{-3}$ ) fabricated in the literature. As shown in the Ragone plot in Fig. 3f, the $\mathrm{CoNi}_{2} \mathrm{~S}_{4}$ MSC exhibits superior energy density over the binary sulfide based MSCs such as $\mathrm{MoS}_{2}$ $\left(E=6 \mathrm{~mW} \mathrm{~h} \mathrm{~cm}^{-3}\right)^{27}$ and $\mathrm{VS}_{2}\left(E=15 \mathrm{~mW} \mathrm{~h} \mathrm{~cm}^{-3}\right)$ (see Table S1, $\mathrm{ESI} \dagger) .{ }^{28}$ The $\mathrm{CoNi}_{2} \mathrm{~S}_{4}$ MSC exhibits a maximum power density of $2327 \mathrm{~mW} \mathrm{~cm}^{-3}$ even at an energy density of $14.2 \mathrm{~mW} \mathrm{~h} \mathrm{~cm}^{-3}$. This study opens up the possibility of employing ternary sulfides as potential candidate electrode materials for on-chip energy storage with superior volumetric capacitance and energy density.

In summary, we have demonstrated the successful fabrication of a micro-pseudocapacitor based on ternary nickel cobalt sulfide. This was achieved by employing single-step electrochemical co-deposition of nickel cobalt sulfide over transferred reduced graphene oxide (rGO) thin films followed by photoresist lift-off. The fabricated $\mathrm{CoNi}_{2} \mathrm{~S}_{4}$ micro-pseudocapacitor exhibits a maximum areal cell capacitance of $11.6 \mathrm{mF} \mathrm{cm} \mathrm{cm}^{-2}$ with a volumetric capacitance of $211 \mathrm{~F} \mathrm{~cm}^{-3}$. The

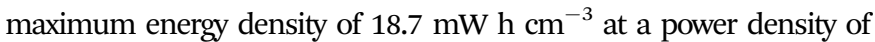
$1163 \mathrm{~mW} \mathrm{~cm}^{-3}$ was achieved, which is superior to the binary sulfide micro-supercapacitors reported in the literature. This study may open up an opportunity to fabricate various kinds of ternary oxide/ sulfide based micro-pseudocapacitors.

Research reported in this publication was supported by King Abdullah University of Science and Technology (KAUST). 
The authors thank the Advanced Nanofabrication, Imaging and Characterization Laboratory at KAUST for their excellent support.

\section{Notes and references}

1 P. Simon and Y. Gogotsi, Nat. Mater., 2008, 7, 845.

2 J. Chmiola, C. Largeot, P. L. Taberna, P. Simon and Y. Gogotsi, Science, 2010, 328, 480.

3 M. Beidaghi and Y. Gogotsi, Energy Environ. Sci., 2014, 7, 867.

4 G. Xiong, C. Meng, R. G. Reifenberger, P. P. Irazoqui and T. S. Fisher, Electroanalysis, 2014, 26, 30.

5 F. Simjee, P. H. Chou, Everlast: Long-life, Supercapacitor-operated Wireless Sensor Node, Low Power Electronics and Design, 2006. ISLPED'06. Proceedings of the 2006 International Symposium on, 4-6 Oct. 2006, pp. 197-202.

6 Z. L. Wang, Adv. Mater., 2012, 24, 280-285.

7 Z. L. Wang and W. Wu, Angew. Chem., Int. Ed., 2012, 51, 11700-11721.

8 D. Pech, M. Brunet, P. L. Taberna, P. Simon, N. Fabre, F. Mesnilgrente, V. Cońed'era and H. Durou, J. Power Sources, 2010, 195, 1266.

9 D. Pech, M. Brunet, H. Durou, P. Huang, V. Mochalin, Y. Gogotsi, P.-L. Taberna and P. Simon, Nat. Nanotechnol., 2010, 5, 651.

10 M. Beidaghi and C. L. Wang, Adv. Funct. Mater., 2012, 22, 4501.

11 J. Lin, C. Zhang, Z. Yan, Y. Zhu, Z. Peng, R. H. Hauge, D. Natelson and J. M. Tour, Nano Lett., 2012, 13, 72.

12 G. Xiong, C. Meng, R. G. Reifenberger, P. P. Irazoqui and T. S. Fisher, Energy Technol., 2014, 2, 897.

13 Z. S. Wu, K. Parvez, X. Feng and K. Müllen, Nat. Commun., 2013, 4, 2487.

14 W. Gao, N. Singh, L. Song, Z. Liu, A. L. M. Reddy, L. Ci, R. Vajtai, Q. Zhang, B. Wei and P. M. Ajayan, Nat. Nanotechnol., 2011, 6, 6.

15 M. F. El-Kady and R. B. Kaner, Nat. Commun., 2013, 4, 1475.

16 T. M. Dinh, K. Armstrong, D. Guay and D. Pech, J. Mater. Chem. A, $2014,2,7170$

17 W. Si, C. Yan, Y. Chen, S. Oswald, L. Han and O. G. Schmidt, Energy Environ. Sci., 2013, 6, 3218.

18 N. Kurra, N. A. Alhebshi and H. N. Alshareef, Adv. Energy Mater., 2014, 4, 1401303.

19 M. Beidaghi and C. L. Wang, Electrochim. Acta, 2011, 56, 9508.
20 K. Wang, W. Zou, B. Quan, A. Yu, H. Wu, P. Jiang and Z. Wei, Adv. Energy Mater., 2011, 1, 1068.

21 C. Meng, J. Maeng, S. W. M. John and P. P. Irazoqui, Adv. Energy Mater., 2014, 4, 1301269.

22 N. Kurra, M. K. Hota and H. N. Alshareef, Nano Energy, 2015, 13, 500.

23 H. Wan, J. Jiang, J. Yu, K. Xu, L. Miao, L. Zhang, H. Chen and Y. Ruan, CrystEngComm, 2013, 15, 7649.

24 S. Peng, L. Li, C. Li, H. Tan, R. Cai, H. Yu, S. Mhaisalkar, M. Srinivasan, S. Ramakrishna and Q. Yan, Chem. Commun., 2013, 49, 10178.

25 W. Chen, C. Xia and H. N. Alshareef, ACS Nano, 2014, 8, 9531.

26 M. D. Stoller and R. S. Ruoff, Energy Environ. Sci., 2010, 3, 1294.

27 L. Cao, S. Yang, W. Gao, Z. Liu, Y. Gong, L. Ma, G. Shi, S. Lei, Y. Zhang, S. Zhang, R. Vajtai and P. M. Ajayan, Small, 2013, 9, 2905.

28 J. Feng, X. Sun, C. Wu, L. Peng, C. Lin, S. Hu, J. Yang and Y. Xie, J. Am. Chem. Soc., 2011, 133, 17832.

29 J. Xiao, X. Zeng, W. Chen, F. Xiao and S. Wang, Chem. Commun., 2013, 49, 11734-11736.

30 W. S. Hummers and R. E. Offeman, J. Am. Chem. Soc., 1958, 80, 1339.

31 D. Li, M. B. Muller, S. Gilje, R. B. Kaner and G. G. Wallace, Nat. Nanotechnol., 2008, 3, 101.

32 M. Shahid, N. Yesibolati, F. M. Ross and H. N. Alshareef, J. Power Sources, 2014, 263, 239.

33 A. C. Ferrari and J. Robertson, Phys. Rev. B: Condens. Matter Mater. Phys., 2000, 61, 14095.

34 M. A. Pimenta, G. Dresselhaus, M. S. Dresselhaus, L. G. Cançado, A. Jorioa and R. Saito, Phys. Chem. Chem. Phys., 2007, 9, 1276.

35 Z.-S. Wu, G. Zhou, L.-C. Yin, W. Ren, F. Li and H.-M. Cheng, Nano Energy, 2012, 1, 107.

36 W. Du, Z. Wang, Z. Zhu, S. Hu, X. Zhu, Y. Shi, H. Pang and X. Qian, J. Mater. Chem. A, 2014, 2, 9613.

37 W. Du, Z. Wang, Z. Zhu, S. Hu, X. Zhu, Y. Shi, H. Pang and X. Qian, J. Mater. Chem. A, 2014, 2, 9613.

38 J. Xiao, X. Zheng, W. Chen, F. Xiao and S. Wang, Chem. Commun., 2013, 49, 11734.

39 J. Xiao, L. Wan, S. Yang, F. Xiao and S. Wang, Nano Lett., 2014, 14, 831.

40 M. Prabu, K. Keptpang and S. Shanmugam, Nanoscale, 2014, 6, 3173. 41 Y. Ohno, Phys. Rev. B: Condens. Matter Mater. Phys., 1991, 44, 1281. 